\title{
INOVAÇÃO INSTITUCIONAL E ESTÍMULO AO INVESTIMENTO PRIVADO
}

\author{
Eduardo da Motta e Albuquerque \\ Professor da Faculdade de Ciências Econômicas da Universidade Federal de Minas Gerais \\ João SICsú \\ Professor do Departamento de Economia da Universidade Federal Fluminense
}

\begin{abstract}
Resumo: Este artigo sugere a criação de uma Agência Especial de Seguros como forma de estimular o envolvimento do sistema bancário privado no financiamento do investimento inovativo e identifica duas dimensões da realidade tecnológica do Brasil: a imaturidade do sistema de inovação brasileiro, indicando a combinação entre escassez (de gastos em P\&D) e desperdício (de oportunidades geradas a partir da infra-estrutura científica); e a incapacidade do sistema bancário em financiar o investimento inovativo.

A proposta dessa agência busca introduzir um rearranjo no sistema de inovação brasileiro, para ampliar os recursos investidos em atividades inovativas sem ter de desviar recursos públicos para financiar o setor privado e sem deslocar recursos comprometidos com a infra-estrutura pública de ciência para a iniciativa privada. Palavras-chave: investimento e ciência; sistema financeiro; pesquisa e desenvolvimento.
\end{abstract}

$\mathrm{E}$ ste artigo sugere a construção de uma Agência Especial de Seguros (AES) como uma inovação institucional que contribui para a superação da incapacidade do sistema bancário brasileiro de financiar o investimento inovador. ${ }^{1}$

A imaturidade do sistema de inovação brasileiro pode ser identificada tanto pelo percentual relativamente baixo de gastos com Pesquisa e Desenvolvimento (P\&D) no país, como pelo desperdício de oportunidades oferecidas pela infra-estrutura científica ao setor produtivo. Para esse quadro de escassez e desperdício contribui de forma sensível a incapacidade do sistema bancário de financiar investimentos de longa duração e, em especial, investimentos inovadores.

Este artigo se apóia em trabalho anterior (Sicsú e Albuquerque, 1998), que apresentou proposta teórica de uma Agência Especial para segurar operações de financiamento de investimentos inovadores, e discute especificamente o caso brasileiro, investigando a adequação dessa inovação institucional.

\section{A IMATURIDADE DO SISTEMA NACIONAL DE INOVAÇÃO}

Uma avaliação geral do sistema de inovação do Brasil pode ser compilada a partir dos estudos abrangentes de
Coutinho e Ferraz (1994), Schwartzman (1993) e Coutinho e Suzigan (1990), que apresentaram uma avaliação detalhada da estrutura industrial, do sistema de ciência e tecnologia e da infra-estrutura educacional do país. Uma compilação desses ricos estudos pode sustentar a avaliação do caráter imaturo do sistema de inovação brasileiro (Albuquerque, 1999). O dado mais revelador e sintético é a porcentagem do PIB brasileiro destinado a atividades de P\&D: 0,8\%, enquanto a média dos países do G-7 é de $2,4 \%$. Outra diferença importante em relação aos países mais avançados, é a participação maior do setor público nas atividades de $\mathrm{P} \& \mathrm{D}$ existentes no Brasil (aproximadamente $70 \%$ do total no caso brasileiro, contra $45 \%$ no caso americano e $20 \%$ no caso japonês, segundo dados de Nelson, 1993).

O sistema de inovação brasileiro encontra-se em uma situação intermediária no cenário internacional. Embora não faça parte do conjunto de países com sistemas de inovação inexistentes, possui características comuns a sistemas também incompletos e, por outro lado, outras identificadas com países de sistemas maduros.

A partir de estatísticas de patentes (Albuquerque, 2000), foi possível identificar características comuns a países mais avançados: firmas nacionais (privadas e estatais) como líderes na obtenção de patentes; indícios de firmas multitecnológicas; distribuição do número de patentes em 
forma de "U", de acordo com o tamanho da firma; elasticidade intersetorial P\&D-patentes, compatível com os valores encontrados na literatura.

Características comuns a outros sistemas imaturos foram encontradas:

- participação elevada das patentes de indivíduos;

- baixo envolvimento das firmas em atividades inovadoras;

- falta de continuidade das atividades de patenteamento;

- baixa sofisticação da divisão de trabalho inter-firmas;

- papel declinante do setor produtor de bens de máquinas e equipamentos;

- caráter predominantemente adaptativo das atividades tecnológicas das firmas estrangeiras;

- diferenças entre a patenteação no INPI e no USPTO (United States Patent and Trademark Office), indicando que alguns setores que são líderes no patenteamento interno praticamente desaparecem nas estatísticas do escritório americano de patentes.

Um aspecto particular da imaturidade do sistema de inovação brasileiro, característica comum a outros sistemas também imaturos, como o da Índia e do México (Albuquerque, 1999), é de especial interesse aqui: o desperdício de oportunidades criadas pela infra-estrutura pública de pesquisa. Para uma avaliação geral da relação entre a atividade científica e a atividade tecnológica, é possível utilizar um Indicador de Aproveitamento de Oportunidades (IAO) (Albuquerque, 1997). Esse indicador é construído a partir de duas proxies. A primeira é a participação relativa do país no total mundial de artigos científicos publicados: uma proxy das atividades científicas do país. A segunda é a participação relativa no total de patentes concedidas pelo USPTO: uma proxy das atividades tecnológicas executadas pelo país em questão. Ambas as proxies têm problemas (Velho, 1987; Griliches, 1990), mas contêm valiosas informações.

O Indicador de Aproveitamento de Oportunidades é calculado dividindo-se a participação relativa no total de patentes concedidas pelo USPTO pela participação relativa no total mundial de artigos científicos. Qual o significado do IAO? Dada a complexidade da relação entre ciência e tecnologia, a comparação entre as duas participações relativas deve apresentar indícios da qualidade da interação entre elas. A avaliação da interação entre a ciência e a tecnologia é um aspecto importante da avaliação dos sistemas de inovação. A suposição básica, derivada da fundamentação teórica dos sistemas nacionais de ino- vação, é que firmas, universidades e centros de pesquisa devam ter um grau razoável de interação. Caso haja um fosso grande entre essas instituições constitutivas do sistema de inovação, isto deve se refletir em um baixo nível de interconectividade do sistema. Esse indicador pode contribuir para oferecer pistas sobre a qualidade dessas conexões.

Para o tema deste artigo, o ponto importante na avaliação do indicador de aproveitamento de oportunidades é a posição do subconjunto, no interior do qual está localizado o caso brasileiro. O Brasil possui um IAO igual a 0,15 . Encontra-se, portanto, entre os países de IAO mais baixo, inferiores a 0,26, ao lado de México, Argentina e Índia, todos países com sistemas imaturos. Os países mais desenvolvidos têm IAO maior, sendo que os países que fizeram processos de catching up no século XX (Japão e Coréia do Sul) possuem os IAOs mais elevados. No caso dos Estados Unidos, há um razoável equilíbrio entre as produções científicas e tecnológicas (IAO = 1,5). O Reino Unido possui o menor IAO entre os países desenvolvi$\operatorname{dos}(\mathrm{IAO}=0,40)$.

Nos sistemas imaturos, a participação do setor científico é razoavelmente superior à produção do setor industrialtecnológico, determinando o IAO baixo. Daí deriva-se o diagnóstico da existência de desperdício de oportunidades. Em termos agregados, o conjunto da infra-estrutura científica parece estar gerando informações e conhecimento não utilizados de forma apropriada pelo setor industrial e tecnológico.

Dessa avaliação sumária do estágio de construção do sistema de inovação no país, duas questões particulares cobram da interface com o sistema financeiro respostas originais. Em primeiro lugar, há a necessidade de ampliação dos gastos nacionais com $\mathrm{P} \& \mathrm{D}$, com destaque para um envolvimento maior e mais sistemático das firmas privadas nessas atividades. Em segundo lugar, o potencial existente nas atividades da infra-estrutura científica do país sugere a necessidade de instrumentos que possam reduzir o desperdício de oportunidades diagnosticado anteriormente.

\section{DEBILIDADES DO SISTEMA FINANCEIRO BRASILEIRO}

Um elemento importante da imaturidade do sistema de inovação brasileiro é a baixa articulação com o sistema financeiro, que aliás, possui uma incapacidade estrutural em conceder financiamentos de longa duração. Esta seção avalia essa incapacidade estrutural e discute se as 
mudanças que o sistema financeiro tende a sofrer no país representarão a superação dessa incapacidade estrutural.

$O$ investimento em P\&D envolve algumas especificidades técnicas e econômicas que têm determinado a forma de seu financiamento, como o seu longo período de maturação e a necessidade de um volume elevado de recursos. Tais características geram uma aguda incerteza devido aos riscos técnicos e de mercado envolvidos. O elevado volume de recursos necessários deveria induzir as firmas inovadoras a solicitar recursos de terceiros. Contudo, os elevados riscos tendem a inibir as firmas inovadoras a recorrer a essas fontes. A opção de grande parte delas, mundo afora, tem sido o autofinanciamento já que, além dos fatores que inibem a demanda, a oferta de recursos para o financiamento externo é reduzida ou, até mesmo, inexistente, em decorrência das incertezas envolvidas.

Segundo Zysman (1983), há três sistemas de financiamento do investimento em geral, e conseqüentemente, do investimento inovativo: os sistemas de mercado de capitais, os sistemas de crédito privado e os sistemas de crédito público. O primeiro modelo pode ser exemplificado especialmente pela forma de financiamento do investimento nos Estados Unidos e na Inglaterra. Nesses países, é privilegiado o canal do financiamento direto via emissão de papéis (ações, debêntures, etc.) pela firma investidora que busca captar os recursos do público poupador. No segundo sistema, os bancos proveêm as firmas de crédito de longo termo, caso da Alemanha. No terceiro sistema, semelhante ao segundo, o governo garante a oferta de crédito de longo termo. Instituições públicas, tais como bancos de desenvolvimento e agências de fomento, realizam essa oferta, como é o caso da França. Alternativamente, o governo pode, em vez de participar diretamente do sistema de financiamento, impor uma série de regras para dirigir o sistema de crédito privado para o financiamento de longo termo, caso do Japão.

O sistema brasileiro de financiamento de recursos para o investimento em P\&D, basicamente de autofinanciamento, não encontra lugar na taxonomia de Zysman (1983). Em relação aos gastos com P\&D, de 1993 a 1998, os recursos investidos foram basicamente autofinanciados e somente uma reduzida parcela foi financiada por fontes externas que são as agências públicas (BNDES, Finep, etc.), as agências internacionais, o Sebrae, os bancos privados e outras fontes que subsidiam ou praticamente doam recursos para esse fim. Dados da Anpei mostram que nesse período, 1993-98, a parcela autofinanciada dos recursos investidos nunca foi inferior a $90 \%$. Embora os dados fornecidos pela Anpei não revelem, sabe-se que as fontes externas são fundamentalmente fundos fiscais e créditos oficiais e, certamente, a participação dos bancos privados deve ser quase nula no financiamento do investimento inovativo.

Isso ocorre no Brasil porque o mercado de capitais e, especificamente, o mercado de ações é bastante débil, assim como não existe uma vocação do sistema financeiro brasileiro para se transformar em um sistema de crédito, em qualquer das versões destacadas na classificação de Zysman (1983). Cabe ressaltar, portanto, que até mesmo o investimento não-inovativo é fortemente autofinanciado na economia brasileira. Segundo Lees, Bott e Cysne (1990), durante os anos 80, a parcela dos gastos autofinanciada nas empresas privadas nacionais era de aproximadamente $77 \%$, enquanto as empresas privadas estrangeiras utilizavam quase $88 \%$ de recursos próprios para financiar os seus gastos.

A causa da debilidade do mercado de ações é basicamente o reduzido volume de poupança com perfil de longo termo que poderia dar densidade a esses mercados. Os fundos de investimento, por exemplo, administrados pelos bancos, são compostos pelo FIF (Fundo de Investimento Financeiro), por fundo de ações e outros - fundos que, desde sua criação, no início dos anos 90 , são compostos em grande parte por títulos federais e uma reduzida parcela de ações. Nos primeiros meses do ano 2000, segundo dados do Boletim do Banco Central, mais de $70 \%$ do volume de recursos dos fundos de investimento estava direcionado para a aquisição de títulos federais e aproximadamente $8 \%$ para a aquisição de ações.

Outro indicador da debilidade do sistema financeiro brasileiro é a sua concentração em atividades de curto termo. Pode-se identificar uma acentuada tendência de elevação da participação percentual do volume de crédito concedido aos setores que caracteristicamente tomam recursos para operações de curto termo (pessoas físicas e comércio). Enquanto em junho de 1988 essas operações representavam pouco menos de $10 \%$ do total do crédito ofertado pelo sistema financeiro, em outubro de 1999 passam a representar quase $30 \%$ desse total.

De forma oposta, a participação percentual do volume de recursos emprestado pelo sistema financeiro aos setores que particularmente tomam crédito de longo termo (indústria e habitação) apresenta uma ligeira tendência de queda no mesmo período.

Nem mesmo o Plano Real, instituído em julho de 1994, alterou essas tendências, embora tenha criado um clima 
muito mais favorável às atividades reais de longo termo, como a construção de moradias e infra-estrutura e o investimento de ampliação ou de constituição de novas plantas.

Se são reduzidas as poupanças com perfil longo termista, os sistemas de crédito (privado e público, na sua versão japonesa) também não podem ser uma alternativa, porque as instituições financiadoras (para conceder crédito de longo termo) não podem carregar passivos curtos. A participação percentual dos depósitos a prazo no total do passivo dos bancos comerciais era muito baixa no final dos anos 80 para sustentar a concessão de crédito de longo termo. Contudo, cabe ressaltar que os bancos comerciais não possuem horizontes longo-termistas. Os bancos múltiplos, estes sim, que possuem um estrutura de ativos e passivos mais diversificada, poderiam atuar com horizontes maiores. Entretanto, o percentual de participação dos depósitos a prazo nos seus passivos, no final dos anos 80 , era inferior ao percentual alcançado pelos bancos comerciais.

O crescimento acentuado dos depósitos a prazo no passivo dos bancos múltiplos e comerciais, que ocorreu até 1994, não foi devido ao aumento da propensão a poupar em ativos de longo termo, mas simplesmente porque esses eram ativos que protegiam os recursos monetários de seus possuidores em um contexto de inflação alta e crônica; além disso, seu prazo de resgate era bastante reduzido, e por vezes, dependendo do volume de recursos e de outras condições impostas pelos bancos, podiam ser resgatados em apenas um dia. O que pode ser observado, após a estabilização, a partir de julho de 1994, é que o percentual de depósitos a prazo, em relação ao total do passivo dos bancos múltiplos e comerciais, volta a declinar atingindo patamares semelhantes àqueles do final dos anos 80. A única diferença, recentemente, é os bancos múltiplos estarem captando depósitos a prazo em proporção maior (relativamente ao total de seus passivos) do que os bancos comerciais.

A ausência de poupadores longo-termistas também se deve a fatores associados ao sistema financeiro. Por exemplo, a inexistência de instituições captadoras de grande porte e com tradição que desfrutem da confiança do público potencialmente poupador de recursos a longo termo e, paralelamente, a inexistência de mecanismos reconhecidamente eficazes de proteção das poupanças (isto é, mecanismos de controle de riscos das operações das instituições captadoras) podem ser considerados como fatores inibidores da realização de poupanças longo-termistas.
Nada indica que esse quadro deva mudar. Pelo contrário, a tendência do sistema financeiro internacional que será seguida no Brasil, em virtude da entrada de um grande número de bancos estrangeiros no País a partir de 1995, deverá manter ou agravar a situação de precariedade do financiamento externo ao investimento em P\&D. A tendência do sistema financeiro internacional é o aprofundamento do processo de desintermediação financeira e o alargamento dos mercados de dívidas securitizadas. Desintermediação é o termo utilizado para designar o processo que os bancos estão há algum tempo desenvolvendo, principalmente nos Estados Unidos, onde reduzem suas operações de concessão de crédito e, simultaneamente, ampliam o volume de operações menos arriscadas de realização de negócios diretos entre poupadores e investidores, chamadas de securitização.

A emissão de papéis por firmas investidoras para a aquisição direta por parte de instituições poupadoras com perfil longo-termista é uma tendência crescente do sistema financeiro internacional e, além disso, uma tendência alternativa aos sistemas de crédito privado e público em que as instituições carregam o risco inerente das operações de concessão de empréstimos e os seus custos mais elevados, devido às restrições regulatórias (reservas mínimas) e às formas específicas desses negócios (por exemplo, o estudo de cadastro). Essas operações não são recentes, pois as grandes corporações e instituições poupadoras longotermistas já participam dos mercados de dívidas há muitos anos. As empresas menores ou que realizam investimentos com maiores riscos não têm tido acesso a essa fonte porque não possuem a tecnologia dos negócios desse mercado, ou porque representam um elevado risco para o poupador (emprestador).

Sendo assim, quando o processo de desintermediação ocorrer no Brasil, tal transformação muito provavelmente não mudará a situação de escassez do investimento em $\mathrm{P} \& \mathrm{D}$. As empresas investidoras em $\mathrm{P} \& \mathrm{D}$, aos olhos dos poupadores, continuarão a emitir papéis com possibilidades bastante arriscadas de negócios recompensadores e, certamente, a tomada de recursos para este fim, mesmo em uma operação direta com o poupador, representará uma possibilidade de financiamento em que o risco do emprestador tende a ser maior do que para projetos nãoinovativos. Ainda que exista demanda por financiamento para o investimento inovativo e haja oferta de fundos para a concessão de empréstimos, a taxa de juros de tal operação seria bastante elevada pelo risco de inadimplência, o que tenderá a tornar inviáveis os empréstimos. 
O que se pode concluir é que a única mudança que se vislumbra no sistema financeiro brasileiro, a desintermediação e a implementação da securitização, não poderá alterar de forma substancial o quadro atual de escassez de demanda e oferta de fundos para o financiamento do investimento inovativo.

\section{AGÊNCIA ESPECIAL DE SEGUROS}

A discussão das duas seções anteriores identificou a imaturidade do sistema de inovação brasileiro, indicando a singular combinação entre escassez (de gastos em P\&D) e desperdício (de oportunidades geradas a partir da infraestrutura científica) e a incapacidade do sistema financeiro em custear o investimento inovativo. A questão agora é investigar como ampliar os recursos investidos em atividades inovativas sem ter de desviar recursos públicos para financiar o setor privado e sem deslocar recursos comprometidos com a infra-estrutura pública de ciência para a iniciativa privada.

É importante salientar que existem um conjunto de instituições, programas e projetos que tentam suprir essas debilidades. A avaliação geral apresentada neste artigo sobre a imaturidade do sistema de inovação no Brasil é um diagnóstico da incapacidade dessas importantes tentativas em superar os problemas apontados na seção II. A proposta da AES, por isso, justifica-se.

Certamente o sistema de inovação brasileiro tem muito a ganhar com mais recursos públicos investidos diretamente em suas instituições. O que se defende neste texto contribui para essa possibilidade, ao explicitamente buscar evitar que recursos públicos sejam destinados para apoiar o setor privado. Em suma, trata-se de investigar uma instituição que contribua para ampliar os recursos que o setor privado investe em atividades inovativas. Para tanto, o objetivo deve ser o de criar mecanismos que estimulem o envolvimento do setor financeiro com as atividades inovativas - e não recursos públicos.

Deixado à própria sorte, o sistema financeiro brasileiro não desenvolverá as características necessárias para o financiamento do investimento inovativo. A proposta de uma AES foi apresentada como sugestão para superar um problema identificado a partir da avaliação das características do investimento inovativo. Trata-se agora de justificar porque essa Agência é necessária e adequada para o caso brasileiro.

Sicsú e Albuquerque (1998:687-689) sintetizaram a proposta da AES. Os argumentos principais, extraídos daquele texto, são os que se seguem.
Dadas as condições de incerteza inerentes às atividades de $\mathrm{P} \& \mathrm{D}$ que geram reduzidos financiamentos para estas atividades e o conseqüente subinvestimento neste segmento da economia, sugere-se a intervenção do setor público. O objetivo dessa intervenção seria diminuir tais condições desfavoráveis, uma vez que o mercado é incapaz de minorá-las. Propõe-se a criação de uma Agência Especial de Seguros que realize algum tipo de seguro não-tradicional dos financiamentos dos investimentos privados em P\&D. A Agência pagaria uma indenização ao banco emprestador, que recuperaria uma parcela dos recursos comprometidos caso o projeto fracassasse por razões estritamente tecnológicas. O objetivo seria pagar uma indenização que satisfizesse parte da demanda por segurança desejada pelo investidor potencial em P\&D e por seu financiador. O pagamento de uma indenização muito abaixo das necessidades do potencial-inovador e de seu financiador inibiria a decisão de investir, por outro lado, uma indenização muito elevada desestimularia os esforços necessários ao sucesso do projeto implementado, assim como incentivaria análises bancárias pouco rigorosas sobre o projeto de $\mathrm{P} \& \mathrm{D}$. Uma indenização estratégica, isto é, intermediária (entre aquele valor que inibe a atividade e outro que desestimula e/ou reduz o rigor de análise) seria o ideal.

A AES seria constituída inicialmente por um aporte de recursos públicos, inaugurando um fundo que seria por ela administrado. A partir de sua constituição, tal fundo seria alimentado por recursos privados, decorrentes dos pagamentos que empresários inovadores devem fazer à AES para garantir o direito de seguro de suas operações financeiras relacionadas às suas atividades inovadoras. Espera-se que a proporção de recursos privados cresça ao longo do tempo. $\mathrm{O}$ aporte inicial e constitutivo de recursos públicos tem um papel-chave para a construção da credibilidade da AES. Caso a parcela de recursos de origem pública do fundo venha a ser utilizada, isso indicaria a existência de graves problemas no funcionamento geral do sistema de inovação e de seu financiamento - porque a AES não estaria atraindo recursos privados. A AES, nesse caso, não conseguiria resolver os problemas que motivaram a sua criação. É importante lembrar que as atividades da AES estão entre as atividades cujo resultado negativo (o sinistro) apenas pode ocorrer depois de um certo período de tempo, o que fornece à AES uma importante margem de manobra inicial.

A entidade proposta para compor o sistema financeiro é uma Agência por ser uma instituição semi-au- 
tônoma no interior do Estado que administrará recursos privados de acordo com objetivos públicos (não terá como meta a obtenção de lucros). A entidade proposta é Especial porque não é uma seguradora que aposta contra eventos cuja distribuição de probabilidades existe e é conhecida. É uma Seguradora porque, embora não o seja no sentido estrito do termo, a AES acabará por ser vista por banqueiros e empresários como uma instituição seguradora tradicional que paga indenizações em caso de fracasso.

Por último, a proposição da AES decorre da concepção que não considera apropriadas políticas que sugerem a transferência direta de recursos governamentais para firmas privadas (Nelson e Romer, 1996). Tal política poderia resultar em uma indevida redução da participação do setor público na necessária sustentação da infra-estrutura científica, que possui um papel crucial na divisão de trabalho interinstitucional existente nos sistemas de inovação, ao garantir um pólo da complexa interação entre ciência e tecnologia. Portanto, a discussão teórica realizada sobre o caráter do financiamento do investimento em P\&D foi combinada com uma preocupação adicional: como ampliar os gastos globais em P\&D sem comprometer o financiamento do lado inescapavelmente público do sistema de inovação.

A AES deve contribuir para que o sistema financeiro construa uma ponte com o sistema de inovação. A discussão do caso brasileiro, porém, sugere que a AES deva ser organizada de forma a dar conta das duas questões indicadas anteriormente: ampliar os gastos com P\&D pelo setor privado e fortalecer as possibilidades de transformação do conhecimento gerado/absorvido pela infra-estrutura científica em atividades industriais e tecnológicas (o que significa apoio ao desenvolvimento de novas firmas de base tecnológica).

Por isso, a proposta feita anteriormente deve ser ligeiramente adaptada para as tarefas específicas de um sistema imaturo. As tarefas apontadas, nesse caso, devem ser combinadas com tarefas como as desempenhadas pelo esquema britânico das loan guarantee scheme (LGS) (Goodcare e Tonks, 1996; National Economic Research Associates, 1990; Levitsky e Prasad, 1987). Esse esquema foi mencionado em Sicsú e Albuquerque (1998:689690) para apoiar a argumentação da AES. As especificidades do caso brasileiro justificam a inclusão das atividades do LGS entre as funções da AES. Assim, a discussão teórica realizada na seção III pode perfeitamente englobar os empréstimos para a abertura de novas firmas como portando mais risco do que empréstimos para uma firma estabelecida (ou seja, esse tipo de operação envolve uma parcela de risco semelhante à do investimento inovativo). O efeito da criação da AES, portanto, será também o de facilitar esse tipo de operação.

A criação de uma AES rearranja o sistema de inovação brasileiro em quatro dimensões. Em primeiro lugar, a AES constrói uma ponte entre o sistema financeiro e o sistema de inovação, criando condições para que o setor privado canalize recursos para atividades inovativas e para a criação de novas firmas de base tecnológica.

Em segundo lugar, a entrada dos bancos e poupadores privados no processo de financiamento de atividades inovativas deve ser considerada um importante passo em direção ao amadurecimento do sistema de inovação. O desenvolvimento da capacidade de avaliação, monitoramento e fiscalização de empréstimos para atividades de enorme impacto econômico certamente representa uma importante mudança estrutural de um sistema financeiro incapaz de sair de um limitado horizonte de curto termo.

Em terceiro lugar, o setor público tem papel-chave no financiamento e no aprimoramento da infra-estrutura científica do país. A criação da AES retira de entidades voltadas para o fomento da atividade científica a responsabilidade de injetar recursos para a viabilização do aproveitamento comercial de novos conhecimentos.

Em quarto lugar, as agências que hoje aprovam projetos e destinam recursos para novas firmas e atividades inovativas (Finep, BNDES, Sebrae, Fapesp, etc.) têm uma contribuição importante para a constituição da AES: o know-how acumulado na avaliação de projetos e de sua viabilidade será útil para a preparação da capacidade técnica que a AES precisa ter. Nesse sentido, mesmo os bancos privados podem se beneficiar dessa capacitação já acumulada. Há um remanejamento de tarefas no interior dessas instituições. Bancos de fomento, uma vez liberados da função de destinar recursos para o setor privado, poderiam concentrar suas tarefas na execução de políticas industriais visando o amadurecimento do sistema de inovação brasileiro e o fortalecimento do sistema de bem-estar social.

Enfim, a criação da AES reorganiza o sistema de inovação brasileiro, ampliando o número de agentes que atuam no sistema de inovação e definindo uma divisão de trabalho inter-institucional mais precisa.

\section{CONCLUSÃo}

A proposta de uma inovação institucional caracterizada pela criação de uma AES parte de uma avaliação do 
estágio de construção do sistema de inovação brasileiro e do grau de funcionalidade do sistema financeiro. É importante destacar que o caráter imaturo do sistema brasileiro de inovação enfatiza a existência de elementos que devem ser utilizados para o seu amadurecimento, em especial a infra-estrutura científica constituída, um importante ponto de partida. A presença de firmas (e não indivíduos) como líderes na patenteação é um outro ponto de partida importante.

O sistema financeiro brasileiro, por outro lado, em que pesem as limitações discutidas no texto, é expressivo. Existem instituições poderosas que possuem condições de cumprir um papel crucial de apoio a um processo de desenvolvimento.

A proposta da AES, portanto, é adequada ao estágio atual de construção tanto do sistema de inovação como do sistema financeiro, pois basicamente busca o estabelecimento de uma ponte entre ambos. Construída essa ponte, um enorme passo em direção ao amadurecimento do sistema de inovação brasileiro poderá ser dado.

\section{NOTAS}

E-mail dos autores: albuquer@cedeplar.ufmg.br e jsicsu@domain.com.br 1. Este artigo sintetiza os principais argumentos de trabalho em desenvolvimento (Sicsú e Albuquerque, 2000).

\section{REFERÊNCIAS BIBLIOGRÁFICAS}

ALBUQUERQUE, E. "Notas sobre os determinantes tecnológicos do catching up: uma introdução à discussão sobre o papel dos sistemas nacionais de inovação na periferia". Estudos Econômicos, v.27, n.2, 1997.
. "National systems of innovation and non-OECD countries: notes about a tentative typology". Revista de Economia Politica, v.19, n.4, 1999, p.35-42.

. "Domestic patents and developing countries: arguments for their study and data from Brazil (1980-1995)". Research Policy, 2000 (no prelo).

ARROW, K. Essays in theory of risk-bearing. Amsterdam/Londres, North Holland, 1971.

COUTINHO, L. e FERRAZ, J.C. (coords.). Estudo sobre a competitividade da indústria brasileira. Campinas, Papirus/Unicamp, 1994.

COUTINHO, L. e SUZIGAN, W. Desenvolvimento tecnológico da indústria e a constituição de um sistema nacional de inovação. Campinas, IE/Unicamp, 1990.

GOODCARE, A. e TONKS, I. "Finance and technological change". In: STONEMAN, P. (ed.). Handbook of the economics of innovation and technological change. Cambridge, Mass., Basil Blackwell, 1996.

GRILICHES, Z. "Patent statistics as economic indicators: a survey". Journal of Economic Literature, v.28, 1990, p.1.661-1.707.

LESS, F.; BOTTS, J. e CYSNE, R. Banking financial deepning in Brazil. Nova York, St. Martin's Press, 1990.

LEVITSKY, J. e PRASAD, R. "Credit guarantee schemes for small and medium enterprises". World Bank Technical Paper. Washington, n.58, 1987.

NATIONAL ECONOMIC RESEARCH ASSOCIATES. An evaluation of the loan guarantée scheme. Research Paper prepared for the Department of Employment. Londres, n.74, 1990.

NELSON, R. e ROMER, P. "Science economic growth, and public policy". Challenge, mar.-abr. 1996, p.9-21.

NELSON, R. National innovation systems: a comparative analysis. Nova York, Oxford, Oxford University, 1993.

SCHWARTZMAN, S. Ciência \& tecnologia no Brasil: uma nova política para um mundo global. São Paulo, FGV/Eaesp, 1993 (Série Ciência e Tecnologia no Brasil).

SICSÚ, J. e ALBUQUERQUE, E. "Financiamento do investimento em P\&D, risco e seguro: uma abordagem não-convencional". Revista Brasileira de Economia, v.52, n.4, 1998, p.675-696.

O envolvimento do sistema financeiro com as atividades de $P \& D$ : o papel de uma Agência Especial de Seguros no Brasil. Belo Horizonte/Rio de Janeiro, 2000, mimeo.

VELHO, L. "The author and the beholder: how paradigm commitments can influence the interpretation of research results". Scientometrics, v.11, n.12, jan. 1987, p.59-70.

ZYSMAN, J. "Governments, markets and growth: financial systems and the politics of industrial growth". Nova York, Cornel, 1983. 